\title{
Nova Iryanthera Warb. (Myristicaceae) da Amazônia
}

\author{
William A. Rodrigues
}

Instifuto Nacional de Pesquisas

da Amazónia, Manaus

Iryanthera inpae W. Rodr., n. sp. (Fig. 1)

Haec species nova foliis simillima cum I. tricorne Ducke, quae autem differt floribus majoribus, perianthio florum masculorum 2,0-2,5 $\mathrm{mm}$. longo, eo florum femineorum 2,5-3,0 mm. longo, androecio 1,5-1,9 $\mathrm{mm}$. longo, androphoro tenui ad basin aliquantum dilatato, fructibus plerumque 1 per infrutescentiam, transverse ellipticis, inconspique carinatis, ad apicem indistincte apiculatis.

Typus: M. Silva et al. 971, Brasil, Amazonas: Estrada Manaus-Porto Velho, entre $\mathrm{km}$ 40-30. Mata de terra firme, solo argiloso. Árvore de $7 \mathrm{~m}$. de aliura $\times 15 \mathrm{~cm}$ de diâmetro; frutos jovens, verdes. Madeira mole, leve, amarelada, passando a róseo, $20 \mathrm{Jul} .1972$. (Holótypus: INPA 100.000; isotypus: NY). $R$.
L. Fróes 26238, Brasil, Amazonas, rio Tefé, Paxiubinha, terra firme alta, floresta alta; árvore de $10 \mathrm{~m}$; flores amarelas. 12 Jun. 1950 (IAN 55135; RB 76772). R. L. Fróes 26281, Brasií, Amazonas, rio Tefé, igarapé Sapiá, terra firme, alta, floresta alta; árvore de $15 \mathrm{~m}$, flores amarelas. 16 Jun. 1950. (IAN 55057). G. T. Prance, D. G. Campbell, J. C. Ongley, J. F. Ramos \& O. P. Monteiro 20540. Brasil, Amazonas, Manaus--Porto Velho Highway, $\mathrm{km}$ south of Igapó Açu. Forest on terra firme. Tree, $5 \mathrm{~m} \times 5 \mathrm{~cm}$. diameter. Fruit green. 14 Março 1974 (INPA 44518, NY). D. G. Campbell, J. C. Ongley \& J. F. Ramos P20885. Brasil, Amazonas, Manaus-Porto Velho Highway, km. 130. Primary forest on terra firme. Tree, $12 \mathrm{~m}$. x $12 \mathrm{~cm}$. diameter. Buds green. 24 Março 1974 (INPA, 44861; NY). Pedro L. B. Lisboa, N. A. Rosa \& M. R. Cordeıro 1573, Brasil, Amazonas, Município de Carauari, 

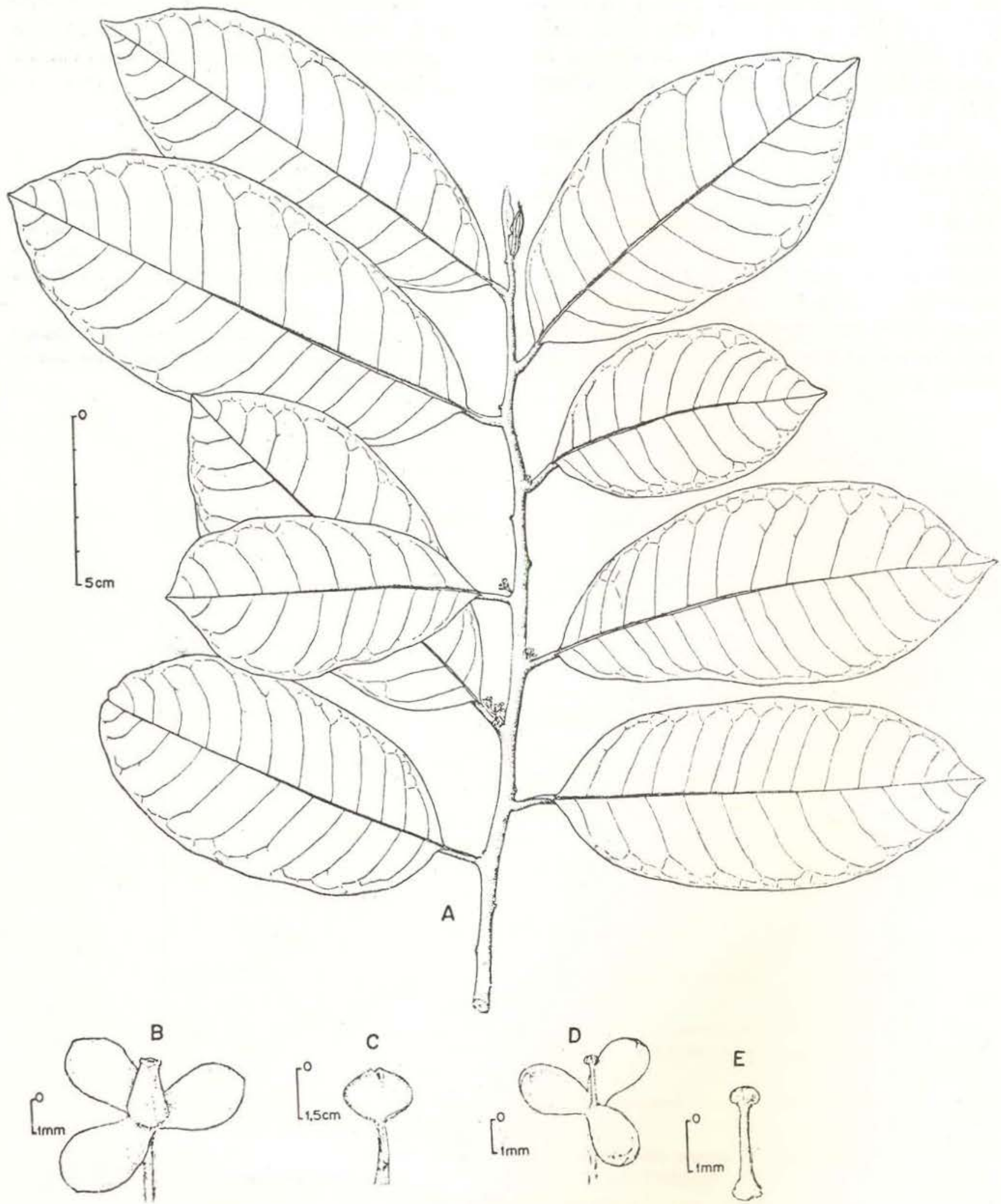

Fig. 1 - Iryanthera inpae W. Rodrigues. A - raminho florifero masculino (D.G. Campbell \& al. P20885); B - flor feminina (M. Silva \& al. 971): C - fruto (G.T. Prance \& al. 20540); D - flor masculina (D.G. Campbell \& al. P20885); E - androceu (D.G. Campbell \& al. P220885). - (Desenho de Alberto C. da Silva). 
rio Juruá, Poço Munguba-1. (MG-1) da Petrobrás, a $32 \mathrm{~km}$. do Porto Gavião ES-50. Solo grey húmido. Árvore de $14 \mathrm{~m}$. de altura $\times 55$ $\mathrm{cm}$. de diâmetro; flor amarela. 18 Out. 1980 (MG, INPA 99653).

Esta nova espécie é muito parecida pela folha com I. tricornis, da qual se distingue pelas flores maiores, perianto das flores masculinas com 2,0-2,5 mm. de comprimento, e das flores femininas com $2,5-3,0 \mathrm{~cm}$ de comprimento, androceu de $1,5-1,9 \mathrm{~mm}$ de comprimento, andróforo delgado e um tanto espessado na base, frutos geralmente um por infrutescência, transverso-elípticos, indistintamente carenados e não apiculados no ápice.
Dedico-a ao Instituto Nacional de Pesquisas da Amazônia como uma homenagem pelo centésimo-milésimo exemplar registrado em seu Herbário.

\section{SUMMARY}

Iryanthera inpae W. Rodrigues is presented as a new species of Myristicaceae from brazilian Amazonia, which is very similar to $\mathbf{I}$. tricornis Ducke in leaf morphology, but differs mainly in the size of the flowers and habit of the fruits.

The specific epithet is in honor of the herbarium number 100.000 of the National Research Institute of Amazonia (INPA). 